\title{
Perceived methods for increasing the productivity of irrigated typical gray and grazing soils of Uzbekistan in non-traditional irrigation
}

\author{
Dilnavoza Burkhanova ${ }^{1,{ }^{*}, \text { Dilrabo Kodirova }}{ }^{1}$, Munisa Urmanova $^{1}$, Muradjan Karimov ${ }^{1}$, \\ and Matlyuba Usmonova ${ }^{1}$ \\ ${ }^{1}$ Tashkent State Agrarian University, University str., 2, Tashkent province, 100140 Uzbekistan
}

\begin{abstract}
This article considers the effective effect of mulching of irrigated typical gray and meadow soils with plant residues and application of various fertilizers on soil fertility, mulching of typical gray soils with plant residues and application of various fertilizers (organic fertilizers, biohumus and biopreparations) in meadow soils. The effect on microbiological activity was determined. The application of various fertilizers (organic fertilizers, biohumus and biopreparations) to typical irrigated gray and meadow soils and mulching of the soil with plant residues have been shown to affect the growth and yield of winter wheat and cotton.
\end{abstract}

\section{Introduction}

Today, scientific research is being conducted in priority areas in the world, such as increasing the fertility and productivity of agricultural crops by improving the properties of degraded soils $[1,2]$. In particular, special attention is paid to the detection of changes in soil cover as a result of degradation processes in irrigated soils, the establishment of organic farming systems, the introduction of technologies to increase the productivity of irrigated soils through the application of organic, mineral, biohumus and biopreparations [2-5].

Uzbekistan is taking comprehensive measures to develop agriculture through the introduction and use of agro-technologies aimed at maintaining and increasing the productivity of degraded irrigated soils, preventing the degradation of irrigated soils and increasing crop yields $[3,5,6]$. Therefore, in the further development of agriculture in Uzbekistan it is important to improve the properties of irrigated soils, mulch the soil with plant residues, increase soil fertility and crop yields through the combined application of organic-mineral fertilizers, biohumus and biopreparations $[2-5,7]$.

Some scientists noted that the application of 10 tons of biohumus per hectare individually or in combination with mineral fertilizers $\mathrm{N}-150, \mathrm{P}_{2} \mathrm{O}_{5}-100, \mathrm{~K}_{2} \mathrm{O}-75 \mathrm{~kg} / \mathrm{ha}$ in relation to the equivalent amount of manure at the expense of soil humus, plant nutrient uptake, growth, development and The effect on productivity was determined [8-10].

\footnotetext{
* Corresponding author: d.burxanova77@,mail.ru
} 
According to the results of such studies [1], taking into account the importance of the feeding background in the cultivation of winter wheat on irrigated soils, they found that the grain yield is higher when wheat is given $\mathrm{N}_{250} \mathrm{P}_{250} \mathrm{~K}_{100} \mathrm{~kg} / \mathrm{ha}$ on a background of 20 tons/ha manure [11-13]. A biopreparation given in the fall washes away nitrogen from the soil through rain and melted snow, while nitrate is trapped in the soil due to low air temperatures. Studies have shown that a biological preparation applied to the soil in the spring has a positive effect on grain quality. The applied "Baikal EM-1" biopreparation shows an increase in winter wheat yield by 13.1 quintal (q)/ha compared to the control.

V. N. Starodubtsev [11] studied the effects of biopreparations and micronutrients on the development and yield of winter wheat. In the conditions of typical black soils of Russia, the addition of straw and "Baikal EM-1" biopreparation to winter wheat increased the yield from 0.14 tons/ha to 0.19 tons/ha. The main source in strengthening the biological condition and fertility of the soil has been proven to be closely related to the life of saprophytic microorganisms. In this case, microorganisms and microbiological processes in the soil have played an important role $[12,13]$. In particular, the presence of organic matter in the soil, nitrogen-fixing microorganisms absorb free nitrogen in the air, due to which it has the property of enriching the soil with biological nitrogen. As a result, in the presence of microorganisms, nitrogen not only accumulates in the soil, but also leads to the assimilation of potassium, phosphorus elements by plants [13, 14]. As a consequence, plants are saturated with biological nitrogen, i.e. environmentally friendly nutrients. Today, due to the development of technology, mineral nitrogen fertilizers are also produced artificially [13-16, 18].

Although a great deal of data has been collected on the dynamics of changes in the amount of microorganisms in the soil throughout the year, there is no consensus among the materials collected by the researchers, and the changing seasons of the earth's seasons are markedly different. This is probably why there are some researchers who believe that the seasons do not significantly affect the change in the number of microorganisms. However, it is unanimously acknowledged by most researchers that not only the seasons themselves, but all the events that take place in them directly affect soil microorganisms.

\section{Materials and methods}

The research is based on two experimental systems for increasing soil fertility through mulching of typical gray and meadow soils with plant residues and application of various fertilizers in Yangiyul and Ortachirchik administrative districts of Tashkent province, Uzbekistan:

- in the case of typical gray soils irrigated, 3 options in 3 replications;

- in the case of irrigated meadow soils, field experiments were carried out in 7 options and 3 replications, and field and laboratory analyzes were performed using generally accepted methods.

The field experiments were conducted according to the manual "Methods of conducting field experiments" developed by scientists of the Scientific Research Institute of Cotton, Uzbekistan [1, 7]. Soil analysis was performed according to E. V. Arinushkina's manual "Manual of chemical analysis of soil", D. G. Zvyagintsev's manual "Methods of soil microbiology and biochemistry", statistical analysis of the results was carried out according to B. A. Dospekhov's manual entitled "Methodology of field experiment" $[8,17,18]$. 


\section{Results and discussion}

According to the results, the studied irrigated typical gray soils are characterized by morphological features such as light gray color, medium sand mechanical composition, humus layer thickness is in the range of $40-80 \mathrm{~cm}$, meadow soils are bluish in color, light and medium sandy, in the lower layers blue spots and gypsum crystals occur, the genetic layers change sharply, the groundwater level is $120-200 \mathrm{~cm}$.

According to preliminary data, in typical gray soils, the volume weight is $1.31 \mathrm{~g} / \mathrm{cm}^{3}$ in the upper layer, depending on the mechanical composition, and $1.33-1.38 \mathrm{~g} / \mathrm{cm}^{3}$ in the subsoil. Specific gravity fluctuates in the range of $2.69-2.72 \mathrm{~g} / \mathrm{cm}^{3}$ along the profile. In irrigated grassland soils, the volume weight is $1.29 \mathrm{~g} / \mathrm{cm}^{3}$, and $1.39 \mathrm{~g} / \mathrm{cm}^{3}$ in the lower layer. The total porosity fluctuates around 49.3-51.3\% along the profile in typical irrigated gray soils, and around $48.1-50.3 \%$ in irrigated grassland soils. According to their mechanical composition, irrigated typical gray soils are classified as medium sandy soils. The amount of physical sludge along the profile of these soils varies from 32.4 to $37.5 \%$. According to the mechanical composition of irrigated meadow soils (option 5), they are light to medium sandy, and the amount of physical sludge varies in the range of 20.6$29.7 \%$.

According to the agrochemical properties, the content of humus in the arable and subsoil layers of typical irrigated gray soils is $0.65-0.81 \%$, total nitrogen $0.046-0.080 \%$, total phosphorus $0.373 \%$, and total potassium $1.37-1.50 \%$. Typical irrigated gray soils are very poorly supplied with mobile phosphorus, the amount of which ranges from 10.0 to $5.33 \mathrm{mg} / \mathrm{kg}$, and those with low exchange of potassium with exchangeable potassium, ranging from 120 to $200 \mathrm{mg} / \mathrm{kg}$. In irrigated grassland soils, the humus content is $0.87 \%$ in the upper layer and decreases to $0.36 \%$ in the lower layer. The total nitrogen content fluctuates around $0.022-0.082 \%$, total phosphorus $0.463-0.123 \%$, and total potassium 1.50 $1.07 \%$. Irrigated meadow soils are also very poorly supplied with mobile phosphorus (4.33$10.0 \mathrm{mg} / \mathrm{kg}$ ), and also poorly supplied with exchangeable potassium, with $200 \mathrm{mg} / \mathrm{kg}$ in the upper layer and $100 \mathrm{mg} / \mathrm{kg}$ in the lower soil layer.

Information on the agrochemical, physical properties of soil, changes in the amount of microorganisms and soil moisture during the growing season, phenological observations in the experimental field and the results of yields for three years under the influence of mulching of typical irrigated gray soils and meadow soils with various fertilizers.

According to the results of the analysis, the amount of humus was $0.30-0.66 \%$ in the driving layer of the control option, and $0.61-0.70 \%$ in the mulched option. During the initial period of field experiments, no significant difference was observed between the options for soil humus supply. During the study, it was observed that as a result of mulching the soil with plant residues, accumulation of organic matter in the soil due to the return of intermediate and siderate crop residues, the humus content in the mulched option increased to the average level $(1.13 \%)$, i.e. $0.19 \%$ compared to the first year.

While the total nitrogen content in the soil fluctuated around $0.067-0.076 \%$, the following year it was observed that the total nitrogen content in the mulched options increased by $0.019 \%$ in the autumn compared to the control. An increase in the amount of nitrogen in the soil indicates the accumulation of organic matter in the mulched options. By the third year, although the total nitrogen content in the cotton planted option decreased in all options in early spring, it was observed that its amount increased in the mulched option due to the decomposition of fertilizer and plant residues returned to the soil in the fall.

Under typical irrigated gray soils, the total phosphorus content fluctuated around 0.208$0.580 \%$ during the first year of the experiment. By the second year, the total phosphorus content was close to each other by crop type, ranging from $0.355-0.598 \%$. Its amount was observed in mulched options. By the third year of the experiment, in the second year, the 
total phosphorus content in the mulched options with plant residues was higher than the control in the upper layers. That is, in the $0-15 \mathrm{~cm}$ layer of the control option, the total phosphorus content was $0.373 \%$, while in the mulched options the figure was $0.458 \%$.

The total potassium content is $2.02 \%$ in the control option and $2.50 \%$ in the mulched option in the tillage layer of the experimental field soil. In the subsoil, its content fluctuates around $1.42-2.00 \%$. According to the results for the second year, the total potassium content was found to be $1.94 \%$ in the third mulched option. Third-year soil analysis showed that under the influence of potassium fertilizers applied in autumn and spring, the amount of total potassium increased sharply compared to the control option, especially in mulched options $(0.237-0.458 \%)$.

Various fertilizers (organic fertilizers, biohumus and biopreparations) applied for three years under irrigated meadow soils were found to have a positive effect on their nutrient content. According to the first year data, in the control option of winter wheat in the control option humus was $0.95 \%$, nitrogen in the form of nitrate 25.6 , mobile phosphorus 17.9 and exchangeable potassium $100 \mathrm{mg} / \mathrm{kg}$, in the option using mineral fertilizers and biopreparations the amount of humus significantly increases were found in $1.06 \%$, nitrogen in nitrate form was 21.6, mobile phosphorus was 23.0, and exchangeable potassium was $118 \mathrm{mg} / \mathrm{kg}$. In the option where biohumus was used, the humus content was $1.05 \%$, nitrogen in the form of nitrate was 25.7 , mobile phosphorus was 20.6 , and exchangeable potassium was $106 \mathrm{mg} / \mathrm{kg}$. In general, the lack of nutrients in the soil during the accumulation phase of wheat can be explained by the increase in the demand for nutrients of wheat during this period.

According to the results of the second year, compared to 2009, the amount of humus in the option with mineral fertilizers and biopreparations increased by $0.14 \%$, in the option with mineral fertilizers and manure by $0.11 \%$, and in the option with mineral fertilizers and biohumus by $0.09 \%$. The amount of nutrients in the soil also fluctuated at different rates throughout the season. For example, nitrogen in the form of nitrate was $22.5 \mathrm{mg} / \mathrm{kg}$ in the spring and $25.1 \mathrm{mg} / \mathrm{kg}$ in the spring when winter wheat sprouted, and by the end of the growing season it was slightly reduced to $21.8 \mathrm{mg} / \mathrm{kg}$.

In our third-year study, the same pattern was maintained. In the case of "Baikal EM-1" biopreparation with mineral fertilizers $\left(\mathrm{N}_{150} \mathrm{P}_{100} \mathrm{~K}_{50}\right)$, the humus content was $1.24 \%$, in the case of mineral fertilizers $\left(\mathrm{N}_{150} \mathrm{P}_{100} \mathrm{~K}_{50}\right)$ it was $1.18 \%$, and in the case of biohumus with mineral fertilizers $\left(\mathrm{N}_{150} \mathrm{P}_{100} \mathrm{~K}_{50}\right) .1 .20 \%$. The highest rate was observed in the option with the use of biopreparation "Baikal EM-1" with mineral fertilizers. During this period, it was observed that the amount of mobile nutrients in the soil decreased by the end of the growing season as a result of plant assimilation of organic matter given to the soil during the growing and development periods of wheat. The highest nutrient content was in the options using mineral fertilizers $\left(\mathrm{N}_{150} \mathrm{P}_{100} \mathrm{~K}_{50}\right)$ and biopreparation "Baikal EM-1" as well as mineral fertilizers $\left(\mathrm{N}_{150} \mathrm{P}_{100} \mathrm{~K}_{50}\right)$ and manure at 20 tons/ha.

During the study, changes in the volume weight and porosity of the studied soils under the influence of mulching and various fertilizers were studied. According to the study, in typical irrigated gray soils, the volume weight of soil in the first year of vegetation was 1.41 $\mathrm{g} / \mathrm{cm}^{3}$ in the control option, $1.29 \mathrm{~g} / \mathrm{cm}^{3}$ in the fully removed and removed cotton stalk option and $1.30 \mathrm{~g} / \mathrm{cm}^{3}$ in the mulched option. At the end of the experiment, these values were reduced to $1.28 \mathrm{~g} / \mathrm{cm}^{3}$ in the control option, $1.24 \mathrm{~g} / \mathrm{cm}^{3}$ in the mulched option, i.e. $0.04 \mathrm{~g} / \mathrm{cm}^{3}$, and the total porosity of the soil under mulching with plant residues relative to the control option. An increase of 5\% was observed (Fig. 1). 


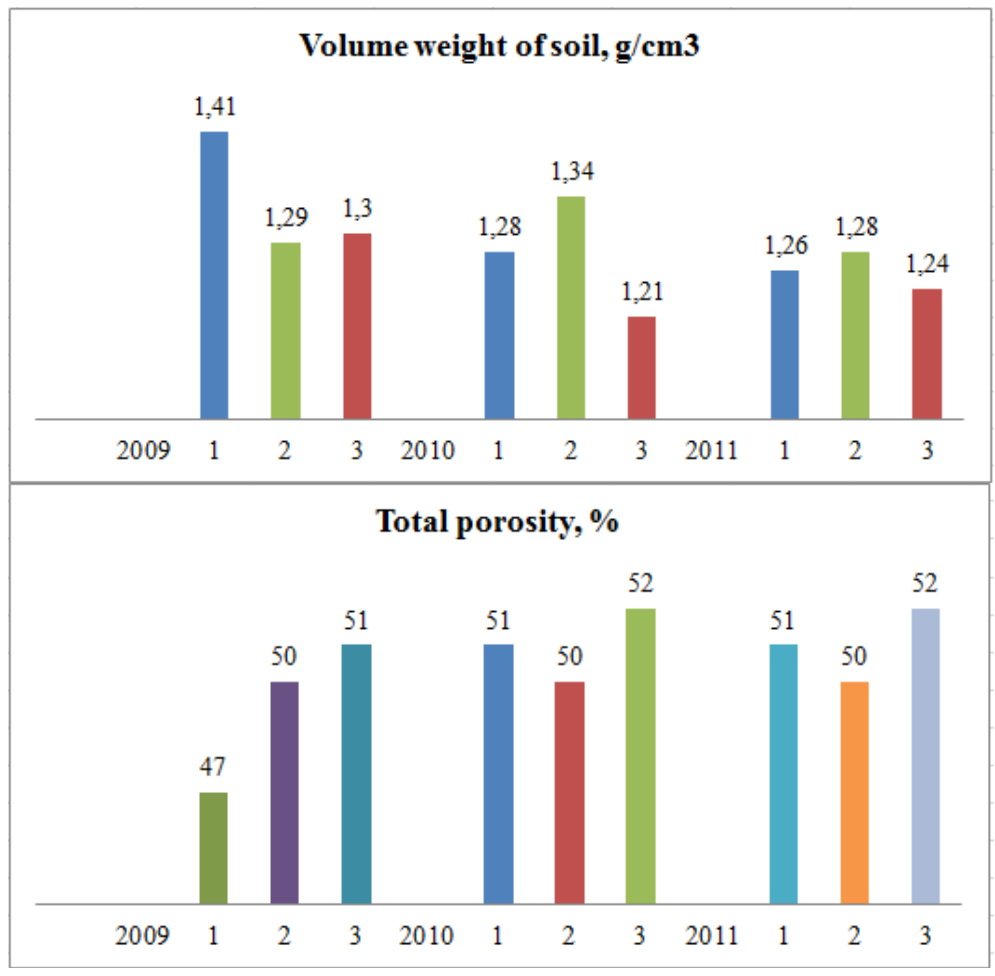

Fig. 1. Changes in the general physical properties of a typical irrigated gray soil.

Thus, mulching the soil surface with plant residues has a positive effect on the accumulation of organic matter in the soil to a certain extent, reducing the volume weight of the soil and increasing its porosity. This in turn leads to an increase in soil fertility.

It has been observed that different fertilizers applied to irrigated grassland soils, i.e. mineral, organic fertilizers and biopreparations, have different effects on the physical properties of the soil.

In the first year of the experiment, the volume weight of soil in the control option during the growing season was $1.35 \mathrm{~g} / \mathrm{cm}^{3}$, in the option with mineral fertilizers and biopreparation "Baikal EM-1" $1.31 \mathrm{~g} / \mathrm{cm}^{3}$, in the option with mineral fertilizers and 20 tons/ha of manure, $1.32 \mathrm{~g} / \mathrm{cm}^{3}$ and mineral fertilizer and 2 tons/ha of biohumus in the applied option was 1.32 g/cm $\mathrm{cm}^{3}$ (Fig. 2). 

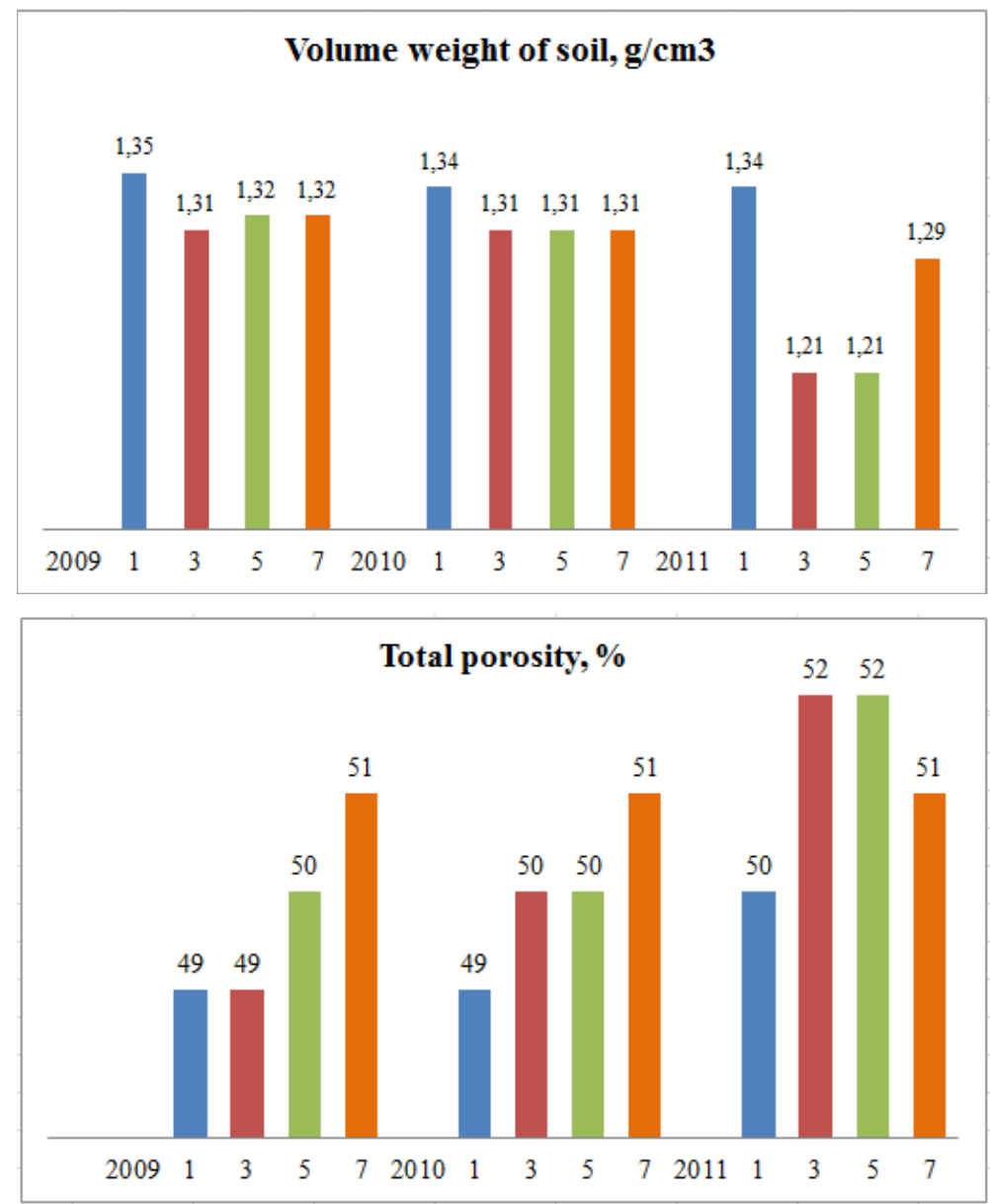

Fig. 2. Changes in the general physical properties of irrigated grassland soils.

By the third year of the experiment, the volume and weight parameters were $0.05 \mathrm{~g} / \mathrm{cm}^{3}$ compared to the control in the option using mineral fertilizers and biopreparation "Baikal EM-1", $0.05 \mathrm{~g} / \mathrm{cm}^{3}$ in the option using mineral fertilizers and 20 tons/ha of manure and 2 tons/ha biogumus was found to be reduced by $0.05 \mathrm{~g} / \mathrm{cm}^{3}$.

The total porosity of the soil was also proportionally $49-51 \%$ in the first year according to the options, and $50-52 \%$ in the third year. Among the experiments, the most optimal indicators of soil volume weight were observed in the options of mineral fertilizers and biopreparation "Baikal EM-1" $\left(1.21 \mathrm{~g} / \mathrm{cm}^{3}\right)$ and mineral fertilizers and manure $\left(20 \mathrm{~g} / \mathrm{cm}^{3}\right)$. These data showed that the combined use of biopreparation "Baikal EM-1" with mineral fertilizers and manure has a positive effect on the volume weight of the soil.

It is known that a significant increase in soil fertility is due to biological processes that take place in the soil. Therefore, the effect of ongoing experiments on the amount of soil microorganisms was studied. Field experiments conducted over the years under typical irrigated gray soils revealed that the number of ammonifiers in the soil at the time of cotton leaf emergence was 5.8 million in the control option, 6.1 million in the mulched option, and 3.0 million more than in the control. In the remaining phases of cotton, these values were observed to decrease relative to the true leaf extraction phase.

It was found that the amount of fungi varies with the amount of ammonifiers during the growing season of cotton. In the phase of 3-4 chin leaves of cotton, an increase in the 
number of fungi and a decrease in the number of fungi was observed as a result of the end of the growing season and an increase in air temperature during the ripening period. In winter wheat, the number of ammonifiers was 3.5 million in the control option, and in the mulched option it was 6.6 million, which is 3.1 million more than in the control option. The same pattern was observed in changes in the number of oligonitrophils and actinomycetes. The increase in the number of microorganisms in the mulched options indicates that the return of cotton stalks, winter wheat straw, siderate and intermediate crop residues to the soil creates favorable conditions for the rapid growth of microorganisms (Fig. 3).

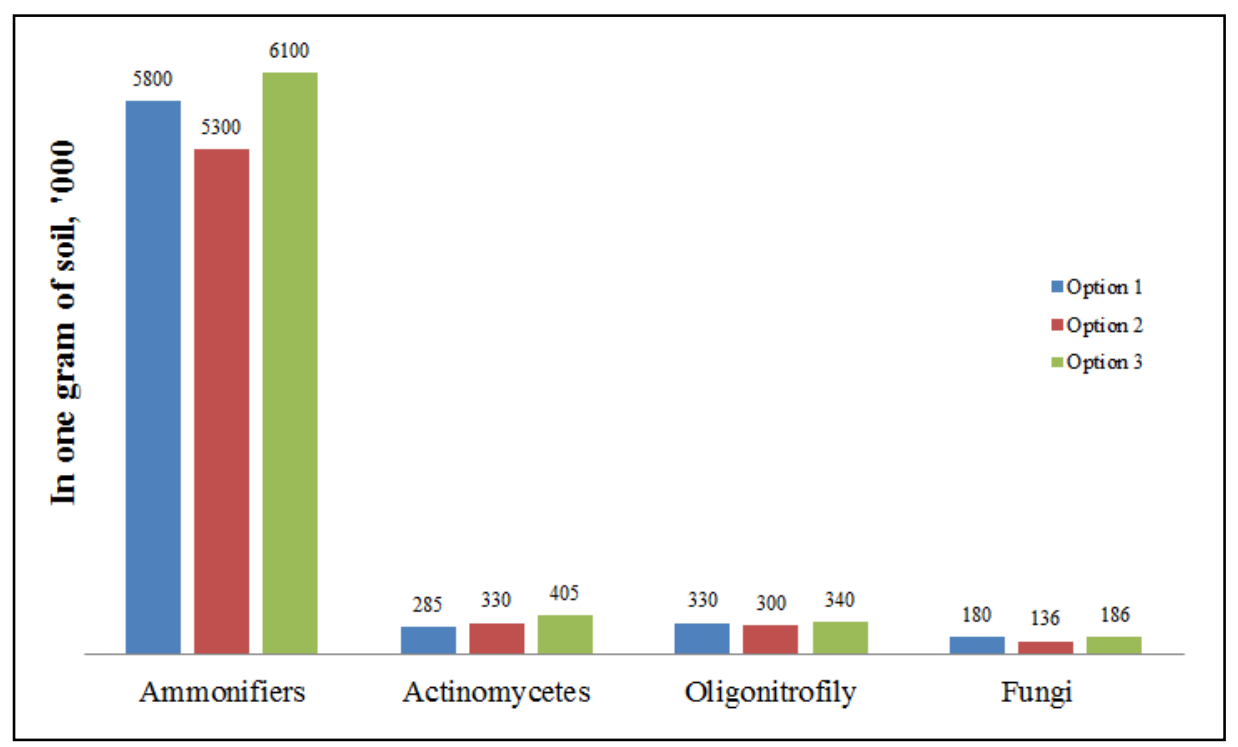

Fig. 3. Influence of mulching on the amount of microorganisms in typical irrigated gray soils (in the phase of cotton leaf emergence).

According to the results of the experiment, the amount of microorganisms varied during the growing season of winter wheat depending on the fertilizers used in irrigated meadow soils. During the germination period, the number of ammonifiers in the upper option of the control option was 2.7 million, 10.0 million in the option using mineral fertilizers and $8 \mathrm{l} / \mathrm{ha}$ biopreparation "Baikal EM-1", 8 in the option using mineral fertilizers and 20 tons/ha of manure. 6 million, and 5.9 million in the option where mineral fertilizers and 2 tons/ha of biohumus were applied. The number of ammonifiers in the germination and full ripening phase of winter wheat was lower than in the germination phase (Fig. 4).

The highest amounts of the remaining microorganism groups (fungi, ammonifiers, and actinomycetes) correspond to the germination phase of winter wheat. This is due to the fact that the germination phase of winter wheat coincides with the spring season, which creates favorable conditions for the growth of microorganisms in the soil. Among the experimental options, the amount of these identified groups of microorganisms was observed to increase by $4-5$ times in the option used in combination with mineral fertilizers and biopreparation "Baikal EM-1". In other words, the number of ammonifiers increased by 10 million, fungi by 425,000 , oligonitrophils by 300,000 , and actinomycetes by $3,200,000$. In addition, higher levels of microorganisms were observed in the options of mineral fertilizers and manure and 20 tons/ha of manure and mineral fertilizers and 2 tons/ha of biohumus. 


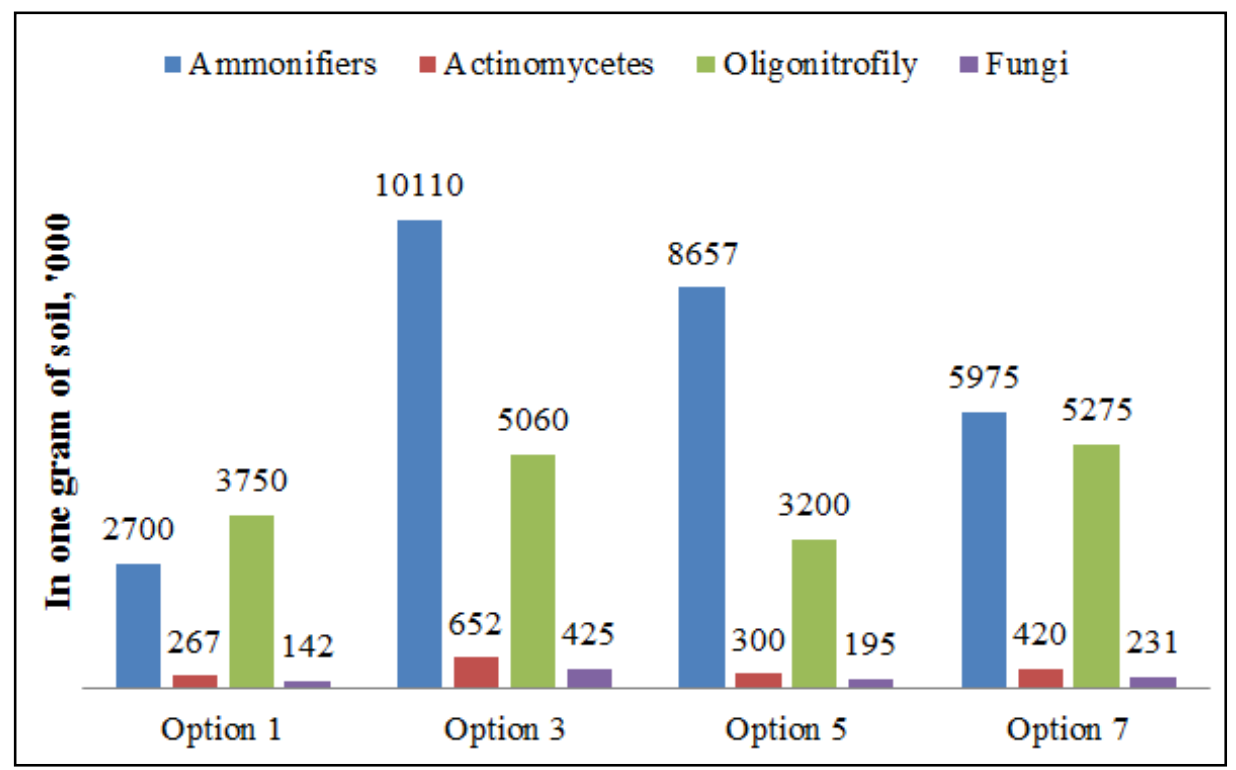

Fig. 4. The effect of different fertilizers on the amount of microorganisms in irrigated grassland soils.

During the experiments on typical irrigated gray soils, the average yield of cotton was $32.4 \mathrm{q} / \mathrm{ha}$ in the control option, $37.2 \mathrm{q} / \mathrm{ha}$ in the mulched option with plant residues, and 4.8 $\mathrm{q} /$ ha more than in the control option.

In the second year, the yield of Sanzar- 8 winter wheat in the experimental field was 39.2 tons/ha in the control option, 41.6 tons/ha in the mulched option, and 2.4 tons/ha more than in the control option. Thus, over the years, it has been observed that mulching soils with plant residues has had a positive effect on soil fertility and high yields from agricultural crops (Table 1).

Table 1. Effect of mulching on cotton and winter wheat yields.

\begin{tabular}{|c|c|c|c|c|c|c|}
\hline \multirow{2}{*}{ Options } & \multicolumn{2}{|c|}{ Years } & \multirow{2}{*}{ 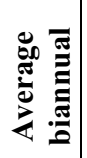 } & \multirow{2}{*}{ 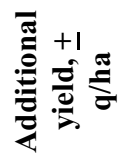 } & \multirow{2}{*}{ 육 $\frac{\bar{\varpi}}{3}$} & \multirow{2}{*}{ 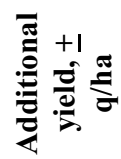 } \\
\hline & $\begin{array}{c}2009 \\
\text { cotton }\end{array}$ & $\begin{array}{c}2011 \\
\text { cotton }\end{array}$ & & & & \\
\hline $\begin{array}{l}\text { 1. Sowing of winter } \\
\text { wheat between rows of } \\
\text { cotton stalks harvested } \\
\text { (traditional sowing } \\
\text { method)+ } \mathrm{N}_{200} \mathrm{P}_{140} \mathrm{~K}_{100}\end{array}$ & 29.5 & 35.4 & 32.4 & - & 39.2 & - \\
\hline $\begin{array}{l}\text { 2. Planting winter wheat } \\
\text { in the background, the } \\
\text { cotton stalks are } \\
\text { completely removed and } \\
\text { removed from the field } \\
+\mathrm{N}_{200} \mathrm{P}_{140} \mathrm{~K}_{100}\end{array}$ & 25.4 & 34.9 & 30.1 & - & 33.6 & - \\
\hline $\begin{array}{l}\text { 3. Crush the cotton } \\
\text { stalks, return to the soil } \\
\text { and plant the winter } \\
\text { wheat }+\mathrm{N}_{200} \mathrm{P}_{140} \mathrm{~K}_{100}\end{array}$ & 32.3 & 42.2 & 37.2 & 4.8 & 41.6 & 2.4 \\
\hline HCP & & \pm 3.15 & & & \pm 4.9 & \\
\hline
\end{tabular}


Over the years, an average of 7,433 $\mathrm{g}$ of stem mass was returned per $1 \mathrm{~m}^{2}$ of cotton, wheat and siderite crops grown in the experimental area.

Thus, in order to maintain soil fertility, cotton stalks, wheat straw and up to twice as much siderite were planted, and their full return to the soil resulted in the enrichment of 3 tons $162 \mathrm{~kg}$ of biomass per 1 hectare for three years.

The average yield of Tanya variety of winter wheat sown in irrigated meadow soils was $32.3 \mathrm{q} / \mathrm{ha}$ in the control option, $45.6 \mathrm{q} / \mathrm{ha}$ in the option with mineral fertilizers and "Baikal EM-1", 20 tons/ha with mineral fertilizers and manure, $44.8 \mathrm{q} / \mathrm{ha}$ and $43.6 \mathrm{q} / \mathrm{ha}$ in the option with mineral fertilizers and 2 tons/ha of biohumus.

The highest additional yield compared to the control option was achieved with the use of $13.3 \mathrm{q} /$ ha of mineral fertilizers and biopreparation "Baikal EM-1". In the options applied with mineral fertilizers and 20 tons/ha of manure and mineral fertilizers and 2 tons/ha of biohumus, the amount of additional yield was 12.5 and $11.3 \mathrm{q} / \mathrm{ha}$, respectively (Table 2).

Table 2. Influence of various fertilizers on the yield of winter wheat variety "Tanya"

\begin{tabular}{|c|c|c|c|c|c|}
\hline \multirow{2}{*}{ Options } & \multicolumn{3}{|c|}{ Years } & \multirow{2}{*}{ 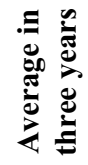 } & \multirow{2}{*}{ 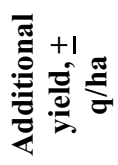 } \\
\hline & 2009 & 2010 & 2011 & & \\
\hline 1. Control without fertilizer & 33.0 & 34.0 & 30.6 & 32.3 & - \\
\hline 2. $\mathrm{N}_{150} \mathrm{P}_{100} \mathrm{~K}_{50}$ & 36.1 & 35.2 & 36.4 & 36.0 & 3.7 \\
\hline $\begin{array}{l}\text { 3. } \mathrm{N}_{150} \mathrm{P}_{100} \mathrm{~K}_{50}+\text { "Baikal } \\
\text { EM-1" biopreparation } 8 \\
\text { l/ha }\end{array}$ & 44.7 & 46.9 & 44.3 & 45.6 & 13.3 \\
\hline 4. Manure 20 tons $/ \mathrm{ha}$ & 37.2 & 37.3 & 38.6 & 37.9 & 5.6 \\
\hline $\begin{array}{l}\text { 5. } \mathrm{N}_{150} \mathrm{P}_{100} \mathrm{~K}_{50}+\text { Manure } 20 \\
\text { tons/ha }\end{array}$ & 44.5 & 45.7 & 44.0 & 44.8 & 12.5 \\
\hline 6. Biohumus 2 tons $/$ ha & 35.7 & 36.2 & 35.2 & 35.7 & 3.4 \\
\hline $\begin{array}{l}\text { 7. } \mathrm{N}_{150} \mathrm{P}_{100} \mathrm{~K}_{50}+\text { Biohumus } \\
2 \text { tons/ha }\end{array}$ & 43.5 & 38.4 & 48.9 & 43.6 & 11.3 \\
\hline HCP & & \pm 3.14 & \pm 1.83 & & \\
\hline
\end{tabular}

The following results were noted on the cost-effectiveness of mulching with plant residues under typical irrigated gray soils: conditional net profit from cotton S-6524 averaged 56,820 UZS/ha in the control option and conditional net profit in the mulched option averaged 138,726 UZS/ha, and the additional income compared to the control averaged $81906 \mathrm{UZS} / \mathrm{ha}$. The profitability rate was $11.1 \%$ in the control option and $26.0 \%$ in the mulched option.

In the conditions of irrigated meadow soils, the conditional net profit from the yield of winter wheat variety "Tanya" averaged 53,306 UZS/ha, in the option with mineral fertilizers and biopreparation "Baikal EM-1" 198,675 UZS/ha, in the options using mineral fertilizers and manure and biohumus. 189,619 and 111,535 UZS/ha, and the additional income in the option where mineral fertilizers and biopreparation "Baikal EM-1" were used for control amounted to $145,369 \mathrm{UZS} / \mathrm{ha}$. The level of profitability was $10.4 \%$ in the control option, $33.0 \%$ in the option using mineral fertilizers and biopreparation "Baikal EM-1". 


\section{Conclusions}

As a result of mulching of irrigated typical gray soils with crop residues (cotton stalks, wheat straw), the amount of humus in the upper $0-15 \mathrm{~cm}$ layer was $0.33 \%$ nitrogen- 6 in the form of nitrate-6, compared to the control due to the return of 3 tons $162 \mathrm{~kg}$ of biomass per 1 hectare for three years: $6 \mathrm{mg} / \mathrm{kg}$, mobile phosphorus $-4.1 \mathrm{mg} / \mathrm{kg}$, and exchangeable potassium $-17 \mathrm{mg} / \mathrm{kg}$. The volume weight of the soil in the mulched option decreased by $0.17 \mathrm{~g} / \mathrm{cm}^{3}$ compared to the control option, and the porosity increased by $5 \%$, the accumulation of sufficient organic matter in the soil as a result of various fertilizers and mulching, improved agrochemical and agrophysical properties. In the typical irrigated gray soils, the amount of microorganisms in the mulched option increased by 3.4 million compared to the control.

When using the biopreparation "Baikal EM-1" $81 /$ ha $+\mathrm{N}_{150} \mathrm{P}_{100} \mathrm{~K}_{50}$ on irrigated meadow soils, the amount of humus in the topsoil was $0.15 \%$, nitrogen $7.3 \mathrm{mg} / \mathrm{kg}$ and mobile phosphorus $5.45 \mathrm{mg} / \mathrm{kg}$, exchangeable potassium $12 \mathrm{mg} / \mathrm{kg}$. In the option using $\mathrm{N}_{150} \mathrm{P}_{100} \mathrm{~K}_{50}$ $+81 /$ ha "Baikal EM-1" the volume weight of the soil decreased by $0.14 \mathrm{~g} / \mathrm{cm}^{3}$ compared to control, in the option using $\mathrm{N}_{150} \mathrm{P}_{100} \mathrm{~K}_{50}+2$ tons/ha biohumus decreased by $0.12 \mathrm{~g} / \mathrm{cm}^{3}$, and the porosity increased by $3 \%$. In the case of $\mathrm{N}_{150} \mathrm{P}_{100} \mathrm{~K}_{50}+81 /$ ha with the use of biopreparation "Baikal EM-1" the amount of microorganisms increased by 18.7 million, and in the case of $\mathrm{N}_{150} \mathrm{P}_{100} \mathrm{~K}_{50}+81 /$ ha with the use of biopreparation "Baikal EM-1" of the variety $13.3 \mathrm{q} / \mathrm{ha}, \mathrm{N}_{150} \mathrm{P}_{100} \mathrm{~K}_{50}+2$ tons/ha biogumus in the combined option yielded an additional yield of $11.3 \mathrm{q} / \mathrm{ha}$.

\section{References}

1. S. A. Aripova, Bulletin of Agrarian Sciences, 2, 12-14 (2003)

2. N. Teshaev, B. Mamadaliyev, A. Ibragimov, S. Khasanov, InterCarto. InterGIS, 26(3), 324-333 (2020)

3. S. K. Isaev, R. U. Rakhmonov, S. S. Tadjiev, G. I. Gozeiv, S. Z. Khasanov, In IOP Conference Series: Earth and Environmental Science, 614(1), 012147 (2020)

4. A. Jumanov, S. Khasanov, A. Tabayev, G. Goziev, U. Uzbekov, E. Malikov, In IOP Conference Series: Earth and Environmental Science, 614(1), 012150 (2020)

5. I. Aslanov, S. Khasanov, Y. Khudaybergenov, M. Groll, Ch. Opp, F. Li, E. Ramirez Del-Valle, In E3S Web of Conferences, 227, 02005 (2021)

6. Z. Mamatkulov, E. Safarov, R. Oymatov, I. Abdurahmanov, M. Rajapbaev, In E3S Web of Conferences, 227, 03001 (2021)

7. A. KH. Kulikova, E. A. Yashin, S. A. Antonova, Bulletin of Ulyanovsk State Academy of Agriculture, 5, 25-29 (2017)

8. K. G. Magomedov, I. M. Khanieva, A. L. Boziev, A. YU. Kishiev, Research Fundamentals, 5, 33-35 (2008)

9. B. Sh. Matyakubov, Z. J. Mamatkulov, R. K. Oymatov, U. N. Komilov, G. E. Eshchanova, InterCarto, InterGIS, 26, 229-239 (2020)

10. M. E. Saidova, Bulletin of Agricultural Sciences, 3(17), 82-84 (2004)

11. V. N. Starodubtsev, Agricultural Sciences, 4, 33-35 (2012) (in Russian)

12. K. Khakimova, I. Musaev, A. Khamraliev, In E3S Web of Conferences, 227, 02003 (2021)

13. S. Isaev, S. Khasanov, Y. Ashirov, T. Karabaeva, A. Gofirov, In E3S Web of Conferences, 244, 02012 (2021) 
14. S. Isaev, S. Khasanov, Y. Ashirov, A. Gofirov, T. Karabaeva, In E3S Web of Conferences, 244, 02047 (2021)

15. R. A. Kulmatov, S. A. Adilov, S. Khasanov, In IOP Conference Series: Earth and Environmental Science, 614(1), 012149 (2020)

16. S. Isaev, I. Begmatov, G. Goziev, S. Khasanov, In IOP Conference Series: Materials Science and Engineering, 883(1), 012080 (2020)

17. L. A. Gafurova, D. A. Kodirova, G. T. Djalilova, O. KH. Ergasheva, Journal of Critical Reviews, 7(2), 292-295 (2020)

18. N. CH. Namozov, D. A. Kodirova, M. I. Usmonova, International journal of scientific \& technology, 9(3), 543-549 (2020) 